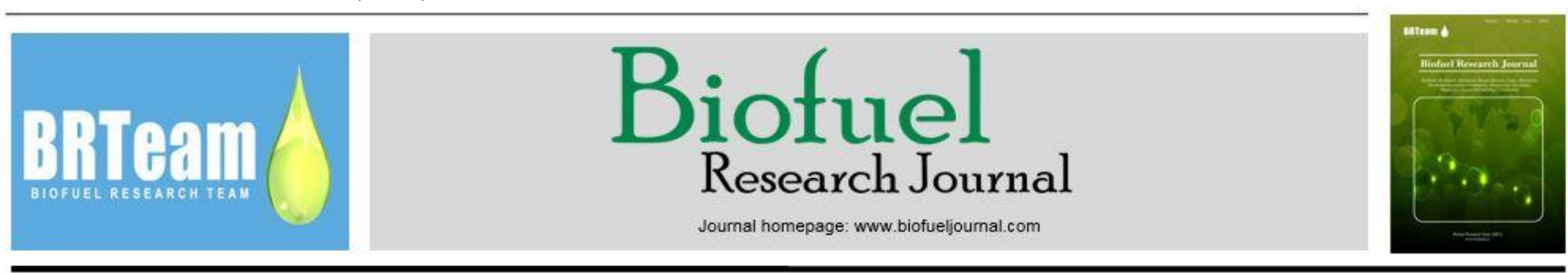

Editorial

\title{
Lignin as a value-added byproduct to improve the economics of lignoethanol?
}

Since the early 1930s the paper industry has relied upon lignin as a source of energy to run its processes. Steam produced during the combustion of lignin in the spent kraft pulping liquor (or "black liquor") is used to generate electricity. Another key use of the steam is for the drying of paper. Based on such practices, the pulp and paper industry has long been regarded as the world's largest industrial user of biofuel.

Since the invention of the kraft pulping process in 1879, the lignin component that is removed from wood during pulping has been regarded as much less valuable in comparison to the cellulosic fibers. The latter can be made into relatively strong paper products, as suggested by the German word "kraft". Over the years, though there have been many ideas of what else might be done with the lignin, no high-tonnage usage has yet been able to motivate the industry to send more than a minor fraction of its lignin to uses other than energy production.

There is an old saying, "you can make anything out of lignin - except money." The consensus has been that the lignin molecule is so inherently complex and heterogeneous that it is difficult to put it to use as a specialized chemical.

But maybe such thinking is outmoded. Maybe the search for value-added applications of lignin has been mired in the inherent deficiencies of kraft lignin. After all, the kraft process, from its inception, was not ever intended to preserve the potential value of the lignin with respect to any usage other than burning. Conditions in the pulp mill were optimized to maximize the carbohydrate component of the wood - with liberation of cellulosic fibers suitable for premium usage in containerboard, fine paper, tissues, and even for Rayon threads or sausage casings.

There is a new generation of scientists and entrepreneurs who look at cellulosic resources in quite a different way. Rather than looking at wood as a source of fibers for paper, this generation is looking at biomass as a source of bioethanol or biobutanol. Rather than treat the polysaccharides gently, they are being subjected to the brutal forces of steam explosion and the intense chemical attack of hydrolysis by concentrated acid at low temperatures or dilute acid at high temperatures. Such treatments tend to expose the cellulose, to subsequent hydrolysis by enzymes, which enable the key transformation to monomeric sugars. Meanwhile the lignin, which is less affected by acids, gets left behind.

The trouble is, the pretreatments that are needed in order to render lignocellulosic material suitable for enzymatic digestion do not come cheap. How is the biofuels industry going to pay for the steam needed to "explode" that biomass and get it ready for liberation of its sugars? Did someone say "steam"? Isn't lignin what is generally used to make steam? Is that a valueadded usage of the lignin?

Sorry, but we almost got side-tracked. Just as in the case of the kraft recovery boiler application, using lignin to make steam is a low-value usage. What we really need in order to make bioethanol and biobutanol processes to look economically attractive is a higher-value using of the lignin.

The so-called "hydrolysis lignin," the byproduct from pretreatment and saccharification of biomass during production of bioethanol, is less degraded than kraft lignin. It ought to have some higher-value uses. Two of the key value-added usages of lignin in past years have been as a flavoring (vanilla), and for the drilling of oil wells (lignosulfonates). As much as I love vanilla ice cream, there is just no way that production of vanillin can put much of a dent in the overall market for lignin. And the lignosulfonates come from sulfite pulping; the demand for drilling muds is likely to be satisfied from conventional wood pulping sources for the foreseeable future.

It has been proposed that lignin can be used as a component of phenolic adhesives. Indeed, lignin is comprised of phenolic units. However, if one looks at a typical representation of the lignin macromolecule, the number of available phenolic groups is quite low - certainly much lower than that of a phenolic component in a phenol-formaldehyde type resin. Also, the presence of methoxyl groups on the aromatic rings within the lignin molecule will tend to block most potential curing reactions involving formaldehyde. In principle, such deficiencies can be overcome by chemical derivatization of lignin. But that raises the cost. Keep in mind that we're looking for a way to prop up the economics of a bioethanol processing plant.

How about carbon fibers? Carbon fibers can be terrifically strong. Their hydrophobic surface makes them promising for various composite applications. Lignin can, in principle, be used as a source of carbon fibers.

But wait. Just when things start to get slightly hopeful for the bioethanol industry, it is not certain that the lignin for future carbon fibers will come from that source. Instead, it seems quite likely that future value-added lignin products may come instead from kraft pulping. Why? Chemical recovery operations at kraft plants are so expensive to build that it often makes sense to remove some of the lignin from black liquor before it is incinerated, i.e., the Lignoboost process. Such a strategy can increase the overall production rate of the pulping operation. Lignin from such a process seems poised to flood the market. High amounts generally imply low prices. And low prices don't add as much value to a fermentation-based biofuels economy.

Editor

Martin A. Hubbe North Carolina State University, Dept. of Forest Biomaterials, Campus Box 8005, Raleigh, NC 27695-8005, USA

Email Address: hubbe@ncsu.edu

Copyright $\odot 2015$ Published by BRTeam

Please cite this article as: Hubbe, M.A. Lignin as a value-added byproduct to improve the economics of lignoethanol? Biofuel Research Journal 8 (2015) 295.

DOI: $10.18331 / \mathrm{BRJ} 2015.2 .4 .2$ 